\title{
La Historia de la Literatura española (1937) de Ángel Valbuena Prat paso a paso (I): origen y resultado de un proyecto editorial ${ }^{1}$
}

\author{
The Historia de la Literatura española (1937) \\ of Ángel Valbuena Prat Step by Step (I): \\ Origin and Result of an Editorial Project
}

\author{
David González Ramírez \\ Universidad de Málaga
}

\section{RESUMEN}

La correspondencia inédita entre G. Gili i Roig y Á. Valbuena Prat nos permite descubrir importantes detalles sobre la génesis y el sinuoso proceso editorial de su original y renovadora Historia de la literatura española, publicada originariamente en 1937, que obligan a rectificar en más de un punto las sospechas que hasta ahora se tenían sobre esta empresa historiográfica. Las primeras cartas del epistolario Valbuena/Gili valoradas en este trabajo (primera entrega de una serie planeada en cinco partes) detallan el origen y la evolución del proyecto, y ofrecen los nombres propios de cuantos se involucraron en él.

Palabras Clave: Ángel Valbuena Prat, Gustavo Gili i Roig, Historia de la literatura, Epistolario, Edición, Guerra Civil, Siglo XX.

\section{ABSTRACT}

The unedited correspondence exchanged between G. Gili i Roig and Á. Valbuena Prat allows us to discover important details about the genesis and the intricate editing process of the original and innovative Historia de la literatura española, originally published in 1937. These new elements help to clarify doubts and dark passages about this historiographical enterprise. The first letters of Valbuena/ Gili's epistolary examined in this work (the first of a five-part series) deal with the origin and the evolution of the project, by providing the names of those who were involved in it.

Key words: Ángel Valbuena Prat, Gustavo Gili i Roig, History of Literature, Letters, Edition, Civil War, 20th Century.

\footnotetext{
${ }^{1}$ Esta contribución se encuadra, como primera parte de un trabajo en cinco entregas, en las líneas de investigación del proyecto «Recepción y Canon de la Literatura Española en el siglo XX» (MICINN. Plan Nacional I+D+i. FFI2013-43451-P), coordinado por José Lara Garrido (Universidad de Málaga).
} 
La opera magna de Ángel Valbuena Prat (1900-1977), su Historia de la literatura española, se convirtió desde su aparición en una obra clásica en los estudios de filología. Su personalidad, su novedad, su claridad y su naturalidad facilitaron que esta Historia haya venido a representar un momento culminante e irrepetible en la historiografía literaria española. Desde que a finales de 1937 viese la luz, en unas circunstancias verdaderamente hostiles, con un comercio editorial bloqueado y en una ciudad, Barcelona, que pronto empezaría a ser sitiada por las fuerzas nacionalistas, varias ediciones fueron las que cuidó su autor hasta aparecer la octava y última, publicada a finales de la década de los sesenta muy aumentada y corregida con respecto a la versión original. A principios de 1980 la obra, revisada y puesta al día con la inapreciable colaboración de Antonio Prieto y Pilar Palomo (quienes realizaron una comprometida labor con el texto que nunca será bien agradecida), recobró entereza y vitalidad para continuar su andadura y mantenerse con solvente equilibro hasta las últimas décadas del siglo XX. Con más de cincuenta años en el mercado editorial, la Historia de la literatura española de Ángel Valbuena merece ser reconocida, por el carisma, la audacia y la sensibilidad que su autor le infundió, como la historia literaria por excelencia del siglo pasado ${ }^{2}$.

El vasto epistolario conservado en la editorial Gustavo Gili entre Valbuena Prat y su editor revela una precisa información hasta ahora desconocida sobre un proyecto en marcha que obliga a rehacer casi de principio a fin la intrahistoria de esta admirable obra. Las cartas nos permiten conocer con detalle el origen de esta empresa historiográfica, sus intermediarios, las fechas en las que se estaba componiendo y concluyendo la obra, las dificultades de

\footnotetext{
${ }^{2}$ En los últimos años, a esta obra le han dedicado varios estudios de alcance y consideración. En la revista Monteagudo, 5, 2000, aparecieron las contribuciones de un homenaje que la Universidad de Murcia (con F. J. Díez de Revenga y F. Florit Durán al frente de la empresa) le tributó a Valbuena Prat en el año de su centenario. De este número interesa tener muy en cuenta el trabajo en colaboración de Palomo y Prieto, así como el de Pozuelo Yvancos (2000). Algunos años más tarde publiqué una amplia monografía sobre la edición encubierta que descubrí de la Historia de Valbuena (2007b); este libro fue prologado con unas páginas iluminadoras sobre la significativa aportación de Valbuena por Lara Garrido (2007). Como precedente de este estudio monográfico apareció un artículo mío (2007a), en que corregía algunos puntos de vista equivocados vertidos en una investigación paralela de Serrano Asenjo (2006) y completaba sus resultados. No mucho más tarde, Martín Ezpeleta (2008) le dedicó un extenso capítulo de su monografía («Ángel Valbuena Prat», en el que reunió, amplió y refundió varios artículos suyos) a la labor historiográfica de Valbuena, centrándose principalmente en su Historia de la literatura española. Pero sin duda alguna, el análisis más exhaustivo y consumado sobre la obra de Valbuena Prat es el que recientemente le ha consagrado Lara Garrido (2012): una exégesis de enorme calado dedicada exclusivamente al ensayo de 1937 que se adentra en «el método historiográfico y la construcción crítica» de la más sugerente Historia de la literatura española; el minucioso trabajo de Lara Garrido completa, perfila y acentúa cualquier aspecto que sobre la personalidad de la obra de Valbuena pueda poner de relieve en esta contribución.
} 
revisión y actualización en los —a veces - interminables procesos de reedición (donde el tráfico de cartas enviadas solía dar lugar a retrasos, malentendidos y extravíos) y, en definitiva, las tensiones que solían crearse por las urgencias del editor (que quería entregar cuanto antes la obra a la imprenta) y las demoras del autor (siempre insatisfecho con los arreglos que le hacía a su obra). Las noticias provenientes de este epistolario imponen en muchos casos una corrección o matización de ciertas noticias indirectas y algunas opiniones vertidas por el propio Valbuena que habían favorecido hasta ahora la creación de una historia equívoca, inexacta e incompleta ${ }^{3}$.

\section{EN LOS ORÍGENES DE UN PROYECTO HISTORIOGRÁFICO: CONFLUENCIA DE INTENCIONES}

Poco antes de ganar por oposición la cátedra de la Universidad de Barcelona a principios 1931 (vacante desde 1928 por la jubilación de Antoni Rubió i Lluch ${ }^{4}$ ), a la que llegaba como reciente historiador de la literatura espa-

${ }^{3}$ Los resultados de esta investigación, que se complementan con otros trabajos en curso de publicación (González Ramírez, en prensa a, b, c y d; una síntesis puede verse ahora en González Ramírez, 2013), no se hubiesen podido ofrecer sin la inestimable colaboración de Mónica Gili (perteneciente a la cuarta generación de la familia que está al frente de la editorial), que me abrió amabilísimamente las puertas de su riquísimo archivo y me ofreció consultarlo con el mayor acomodo y todo el servicio necesario; junto a ella me veo obligado a mencionar a Saskia Adriaensen, siempre atenta y cordialísima. A ambas les debo, además de mi respeto y admiración, un privilegiado agradecimiento. En adelante, para referirme a Valbuena Prat y al editor, Gustavo Gili i Roig (1868-1945), lo haré mediante las iniciales de sus apellidos: VP y GG. Al hijo de este último, Gustavo Gili i Esteve (19061992), me referiré, en esta primera entrega, como GGj.

${ }^{4}$ En una tarjeta postal de principios de 1931 (s.f.), VP se dirigía a su «querido maestro y distinguido amigo» Antoni Rubió i Lluch para notificarle «antes que a nadie», «con verdadera, con inmensa emoción», que había «sido votado para su cátedra de Literatura de la Universidad de Barcelona». Al ver «realizado el sueño ideal» de sus «ilusiones universitarias», VP le confesaba, como «fervoroso discípulo», que se veía repentinamente arrostrando «la responsabilidad de sucederle a Vd., el digno continuador de Milá en la cultura catalana; el representante de una de las más altas cimas del humanismo mediterráneo». En esta sugerente carta, el futuro historiador de la literatura mostraba su «entusiasmo por la cultura catalana» (se sentía «catalán, nacido en Barcelona, y el Prat de mi línea materna representa para mí los mejores recuerdos emocionales») y, recién llegado a su ciudad natal, no ocultaba su deseo de compenetrarse «con ese espíritu que ha vuelto a vivir en tantas formas culturales del Renacimiento catalán desde el siglo XIX». Esta misiva, junto con otras que citaré dirigidas a Rubió i Lluch y a su hijo Jordi Rubió i Balaguer, se conserva en la «Biblioteca Arxiu Rubió», hoy diligentemente custodiada por los hijos de este último, Helena y Antoni Rubió Guilleumas, quienes me permitieron con la mayor amabilidad consultar su rico epistolario. Entre la amplia bibliografía dedicada a estos dos estudiosos de la literatura catalana, resulta sugerente el trabajo de Massot i Muntaner (2005-2006) sobre la figura de Rubió i Lluch a través de la visión de su hijo. De entre lo más reciente y documentado en torno a Jordi Rubió destaca otro trabajo de Massot i Muntaner (2005) que interesa tener en cuenta. 
ñola (sus manuales sobre la Poesía española contemporánea y la Literatura española dramática se editaron en 1930), VP firmó un contrato con la editorial Labor (que auspició la publicación del último libro citado) para preparar una obra de conjunto que se titularía La novela española ${ }^{5}$. Para dar forma y sustancia a ese proyecto, VP se trasladó a mediados de julio al Ateneo de Madrid, que frecuentaba con regularidad en sus viajes a la capital durante el curso académico en La Laguna (cuya cátedra consiguió a finales de 1925). En estas fechas le mandó unas líneas a Jordi Rubió i Balaguer (C: 15-VII-1931) ${ }^{6}$ anunciándole que había «empezado ya a trabajar en el Ateneo, para el tomo de la novela de la "Labor"», y mostraba cierto interés además por las posibles novedades que pudiese tener «de Calvet».

Se refería VP a Agustí Calvet, conocido como «Gaziel», influyente periodista en la década de los veinte y treinta y director de La Vanguardia durante estos comedios. Compañero generacional de Jordi Rubió, con quien le unió una gran amistad (certificada por el nutridísimo epistolario que hoy se conserva de Gaziel en la Biblioteca Arxiu Rubió), comenzó a colaborar a finales de los años veinte como asesor de GG, a quien conocía desde hacía algún tiempo. La relevancia de una figura tan destacada como GG en el universo editorial de las primeras décadas del siglo XX viene acreditada «no tan sols perquè es tracta de l'editor més compromès del període amb els problemes de l'ofici i del llibre, sinó també per l'activisme gremial que desplega» (Llanas, 2005: 123) ${ }^{7}$. Conocido en sus últimos años como «"el patriarca de los editores españoles"»(Palomo y Prieto, 2000: 19), GG aprendió el abecé del mundo editorial junto a su padre, Joan Gili i Montblanch, quien «antes de dedicarse al mundo de los libros, había ejercido múltiples profesiones: profesor de instituto, fabricante de jabones, representante de la papelera Mongolfier» (Permanyer, 1989: 36). No pasaron muchos años hasta que GG inauguró su propia empresa editorial, dedicándose en sus primeros años a los libros de

${ }^{5}$ El contrato está firmado en Barcelona, el 21 de noviembre de 1930. Este documento privado, junto con otros que citaré a lo largo de este trabajo (folletos, cartas personales, etc.), ha llegado hasta mí gracias a la espléndida generosidad de la familia de VP, que ha conservado aquellos materiales que el historiador dejó en sus residencias de Barcelona y Madrid, y con la máxima confianza me ha permitido trabajar con ellos.

${ }^{6}$ Toda documentación reunida en el archivo Gustavo Gili en torno a la Historia de la literatura española hasta 1935 (es decir, todas las cartas cruzadas entre la editorial y el autor que se citarán en esta parte del trabajo, junto al borrador del contrato y su versión definitiva), ha sido compilada en González Ramírez (2012). En adelante, cuando las fechas de las cartas no estén especificadas (muchas de las redactadas por VP carecen de la datación precisa), me basaré - y así lo especificaré — bien en los datos que figuren sobre la fecha de recepción (R:) o contestación (C:) de sus corresponsales, bien guiándome por otros datos orientativos según el contenido (ca.). En la transcripción de las cartas he corregido las erratas evidentes, he uniformado el uso de mayúsculas y minúsculas (principalmente en los títulos de obras citados), he retocado la puntuación cuando ha sido preciso y he modernizado la ortografía conforme a las normas académicas vigentes. 
contenido religioso que había trabajado con su padre; si bien, pronto se inclinó por las traducciones de manuales específicos, las ediciones de autores contemporáneos, las obras de Historia del Arte, etc. Su culto al libro (su biblioteca particular reunía una riquísima variedad de ediciones príncipes, libros de arte, ejemplares raros y curiosos, etc.) le llevó a crear varias colecciones de bibliofilia, como «La Cometa» y «Armiño».

En 1945 GG publicó una obra en la que encerró gran parte de su «experiencia profesional» para tratar de contrarrestar «los problemas de nuestro libro en el momento presente». En el que ha sido considerado como su «testament professional», GG apuntaba a las estadísticas de edición de libros durante la posguerra, a la necesidad de aumentar las traducciones, al bajo índice de lectura y a la falta de profesionalización del escritor (Llanas, 2006: 48-50). En unas sugestivas líneas - claves para configurar la imagen fiel del editor ideal que había intentado ser-, GG (1944: 45) quintaesenciaba los valores que debía atesorar el editor, centrados básicamente en el compromiso moral y en el sentido de la responsabilidad, para no ver desplomadas todas sus aspiraciones:

\begin{abstract}
El editor, al acometer la empresa de publicar libros, arriesga un capital y tienen en sus manos la subsistencia de varias familias que directa o indirectamente dependen de él. Su primer deber moral es no arruinarse, porque arruinándose arrastra consigo a muchos más. Es necesario, pues, que una a sus ideales un sentido práctico del negocio que realiza. Sus actividades son de tal complejidad que exigen cualidades poco comunes en una misma persona. Ha de escoger sus obras procurando que sean buenas, y además que se vendan. Ha de buscar a sus autores, y en muchos casos descubre sus verdaderas aptitudes y orienta su producción. Ha de tener, en suma, conocimientos enciclopédicos para abarcar el vastísimo campo de la producción intelectual. Y ha de saber rodearse de asesores y colaboradores que suplan con sus conocimientos todo lo que el editor necesariamente no alcanza a saber.
\end{abstract}

La ampliación por los años veinte de su proyecto editorial y el aumento de los campos de especialización hacía más acuciante la asistencia técnica a la que

\footnotetext{
${ }^{7}$ En esta obra, Llanas (2005: 123-128), además de diseminar algunas noticias sobre el editor catalán, le dedica un capítulo a «Gustavo Gili: uns fonaments de pedra picada». El volumen que continúa la serie (y en ambos figura la colaboración de M. Ayats), contiene un capítulo (2006: 48-53) referido al Bosquejo de Gili Roig (al que más adelante me referiré), «Gustau Gili i Roig i la política del llibre», y otro (2006: 127-130) en el que se aportan algunos apuntes sobre las líneas editoriales emprendidas por los herederos de la editorial, Gili Esteve, Gili Torra y los hermanos Gili Galfetti, que son quienes hoy están al frente del proyecto: «Gustavo Gili: més de cent anys d'història». Agradezco al profesor Llanas el envío de sus importantes contribuciones bibliográficas, que han mejorado sustancialmente la investigación que ahora presento. A las medidas corporativas y a las iniciativas oficiales impulsadas por GG (particularmente sobre el proteccionismo y el fomento del libro), se ha referido en muchas páginas de su extensa monografía Martínez Rus (2003). Ahora resulta imprescindible tener en cuenta el valioso trabajo de Castellano (2013), para conocer con cierto detalle el ambiente familiar en el que se educó culturalmente GG y el espíritu que acompañó a su empresa editorial.
} 
GG se refería en este párrafo. El editor buscó asesoramiento en diversos profesores de universidad y en otros intelectuales de la época para granjearse la competencia de aquellos especialistas mejor cualificados dentro de las diversas materias en las que pretendía introducirse. A su lado trabajó durante algún tiempo una figura señera de la intelectualidad catalana como Gaziel, cuyo nombre no ha sido jamás relacionado con la Historia de la literatura española de VP, como tampoco lo ha sido el de Jordi Rubió, en la prehistoria editorial de esta obra ${ }^{8}$. Según GGj, «Gaziel y Gudiol asesoraban» a su padre «sobre grandes colecciones de libros de arte en ediciones muy cuidadas» (en Permanyer, 1989: 36), y fue el propio Gaziel quien propuso que Picasso ilustrase uno de las grandes obras publicadas que contiene el catálogo editorial de Gustavo Gili, La Tauromaquia de Pepe Hillo.

Las novedades de Gaziel que VP esperaba — según la citada carta a Jordi Rubió- estaban referidas a un proyecto historiográfico sobre la literatura hispánica e hispanoamericana que se acariciaba desde la editorial. Para perfilarlo Gaziel le planteó a su amigo Rubió sus líneas maestras, y fue este quien reorientó sus dimensiones, aconsejando que se circunscribiese a la literatura española e hispanoamericana, y quien ofreció además las señas de identidad del que con mejores arrestos podía llevar a término al menos la primera parte: Ángel Valbuena Prat ${ }^{9}$. Una reunión frustrada entre los tres para comentar las líneas del proyecto que tenían entre manos nos da la posibilidad hoy de conocer lo que el asesor de GG le hubiese planteado a VP (16-VII-1931):

\begin{abstract}
Me supo mal no poder reunirme con Vd. y con mi viejo amigo Jorge Rubió, como teníamos proyectado. Así me hubiera sido mucho más fácil comunicarle a Vd. la idea que nuestro amigo Rubió ya le había indicado. No obstante, me parece que la cosa es tan clara, que incluso por carta se podrá manifestar brevemente.

El proyecto que yo propuse al editor Gustavo Gili, y que este aceptó en principio, es de publicar una Historia ilustrada de las Literaturas Hispánicas e Hispanoamericanas a imagen de lo que en Francia han hecho Lanson y Bédier, pero englobando aquí la historia de las literaturas castellanas, gallega, catalana y la de la América española.
\end{abstract}

\footnotetext{
${ }^{8}$ VP (1937: 913, n. 1) le dedicó a Gaziel un breve apunte en su Historia de la literatura española a esta personalidad en el apartado «Lo intelectual en el estilo, el pensamiento, la ciencia, la historia». Dentro del «sector catalán» y «en relación con el periodismo y la historia», se refería el historiador a «la importante producción -periodismo y ensayo- de «Gaziel» (Agustín Calvet)». A través de la documentada monografía de Llanas (1998), el lector puede perfectamente reconstruir la personalidad de este intelectual y calibrar la magnitud de su obra periodística y literaria.

${ }^{9}$ Estas primeras cartas nos permiten afinar las hipótesis de Palomo y Prieto (2000: 19), que intuían que VP, «desde que se instaló en su cátedra de Barcelona, no tardó en ponerse en contacto con ese digno colaborador [Gustavo Gili] para su proyecto» y sospechaban también que habría sido su «maestro», «Rubió i Lluch, el eminente medievalista, coetáneo de Gili, quien pudo poner en contacto al anciano editor con el joven catedrático de la Universidad».
} 
Este proyecto ha quedado ahora un poco reducido, porque las atinadas observaciones de Jorge Rubió nos han hecho comprender que tal vez es mejor descartar las literaturas gallega y catalana, dejando únicamente toda la familia de las genuinamente castellanas, es decir, la castellana propiamente dicha y sus hijas de América.

Así, pues, nuestra actual concepción de la obra es:

$1^{\circ}$.- Se titularía Historia ilustrada de las Literaturas Española e Hipanoamericanas.

$2^{\circ}$.-Constaría de tres tomos, dos para la literatura española y uno para las otras.

$3^{\circ}$.-De los dos primeros tomos podría encargarse exclusivamente Vd., cuya competencia erudita y cuya sensibilidad literaria se bastan para tal empeño, y del tomo dedicado a la literatura hispanoamericana podría encargarse a mi excelente amigo Enrique Díez-Canedo, gran conocedor de estas materias.

$4^{\circ}$.-El plan de la obra y su estructura, a nuestro juicio, no tendría que inventarse para nada, pues bastaría seguir como pauta el extraordinario manual de Lanson; creo que no es este un empeño fácil, pero tampoco imposible.

$5^{\circ}$.- Los autores facilitarían, además del texto, todas las indicaciones necesarias para obtener el correspondiente material de ilustración, de suerte que el editor no tuviese más que componer el primero y encargar el segundo.

Le agradecería a Vd. mucho que tuviese la amabilidad de decirme su parecer. Dígame con toda sinceridad cuál es la remuneración que Vd. desearía percibir por su trabajo y en qué forma, así como el plazo aproximado en que Vd. podría entregarlo y el sistema que pensase Vd. adoptar para la entrega sucesiva de materiales.

En caso favorable, supongo que Vd. podría empezar su trabajo en seguida, de manera que se aprovechasen estos meses veraniegos. Yo pienso tomar vacaciones a partir de agosto, de suerte que le agradecería a Vd. muchísimo que tuviese la bondad de darme su contestación lo más pronto posible. Así, si como espero se llega a un rápido acuerdo entre Vd. y el editor, tendré todavía tiempo de escribir a Díez-Canedo, al cual le ruego que, si le es a Vd. posible, le comunique ya en principio el proyecto.

En una posdata manuscrita le indicaba Calvet también el rechazo de Rubió a intervenir en «la confección de esta obra», aunque se reservaba «la esperanza de hacerle escribir más tarde una Historia ilustrada de la literatura catalana» ${ }^{10}$. Aunque el resultado del proyecto editorial se asemejase a la Histoire illustrée de la littérature française (1923-24) de J. Bédier y P. Hazard, y al Manuel illustrée d'histoire de la littérature française (1929) de G. Lanson y P. Tuffrau, cuyo éxito editorial quizá hizo rebrotar en el seno de la editorial Gustavo Gili la necesidad de plantear una obra de análogas condiciones, el paradigma historiográfico que tenía en mente Calvet — remarcado en el cuarto punto de su carta- es el de la Histoire de la littérature françai-

\footnotetext{
${ }^{10}$ Las cartas que citaré de Calvet se conservan también en la editorial Gustavo Gili. Jordi Rubió (1953) acabó asumiendo esta labor que le tenía reservada Calvet en su contribución para la Historia general de las literaturas hispánicas que dirigió años más tarde G. DíazPlaja.
} 
se de Gustave Lanson (1857-1934), una exitosa obra que apareció por vez primera editada a finales del siglo XIX y que su autor mantuvo viva refundiéndola y reeditándola durante varias décadas. Con la elección de la obra de Lanson como punto de partida se aspiraba a alcanzar varios objetivos. En primer lugar se pretendía seguir su carácter metodológico para componer una obra de similar alcance cultural. Para Lanson la Historia Literaria representaba un cruce de caminos con otras disciplinas a las que necesariamente debía atender, como la Filosofía, la Historia o la Sociología; su obra era también una Historia de las Ideas Estéticas y de las corrientes culturales, que alcanzaba hasta su más inmediato presente ${ }^{11}$. Por otra parte, se quería ensayar una obra que tuviese un sello individual e innovador, en el que la caracterización de ideas y la valoración personal estuviesen por encima de la deshumanización crítico-literaria que ensayaban los historiadores tradicionales. Por último, se albergaba la posibilidad de ir adensando y actualizando con el tiempo la obra, al igual que Lanson, que desde que apareciese en 1894 la primera edición de su texto, fue revisándolo y ampliándolo en el tiempo.

A los pocos días de recibir esta carta, VP (19-VII-1931) le escribía a Rubió para pedirle consejo sobre la remuneración que debía percibir y hacerle saber que las directrices del proyecto que acababa de presentarle Calvet le parecían en general «bien». A Gaziel también le respondía (s.f., ca. 19-VII-1931) para agradecerle «su propuesta» y reconocerle que Canedo, «amigo» suyo, podría hacer «un vol[umen] muy interesante» ${ }^{12}$. En cuanto a su labor, finalmente admitía que había «pensado muchas veces en un tipo de manual de Lit[eratura] Esp[añola] a lo Lanson — a pesar de sus dificultades-, y tendré mucho gusto en intentar esta tarea». Le planteaba algunas cuestiones más relativas a «la remuneración» y a «la extensión», y terminaba su carta manifestándole que, mediando un «acuerdo» podría empezar a trabajar inmediatamente y entregar el primer tomo «en junio o julio del año próximo 1932, y el $2^{\circ}$, unos 6 u 8 meses después». Calvet se limitó a advertirle a VP [24-VII-1931] que GG ya estaba al corriente de todo, y que en adelante serían ellos personalmente quienes debían entenderse, con la confianza — profética- de que los «dos llegarán fácilmente a un acuerdo y habrán de ser por largo tiempo buenos amigos y colaboradores». La correspondencia con Calvet desaparece en cuanto GG

${ }^{11}$ Martín Ezpeleta (2008: 121) ya aludió a que el método seguido por VP era similar al «desarrollado por la escuela positivista francesa de Brunetière y su discípulo más aventajado, Gustave Lanson» (recientemente ha vuelto a insistir sobre ello, 2012: 415-416). Para justipreciar las cualidades del manual de Lanson y su rica aportación historiográfica, conviene al menos acudir a las páginas sintéticas de Wellek (1988), Padilla Chasing (2003) y Rubio Tovar (2004).

${ }^{12}$ En su Literatura castellana (1974-1979: 1314) le reconoció a Canedo «el magisterio, más de matiz que de dirección», que había ejercido sobre él en su juventud; admitía VP que le unió «en Madrid y Barcelona» una «cordial amistad», «debida a la simpatía y trato hasta familiar (asistencia a grupos literarios, a obras de teatro, a conciertos, etc.)». 
asume la responsabilidad de esta propuesta. En su primera carta, de interés capital para entender las aspiraciones del editor, GG le explicaba in extenso el origen del «proyecto de publicar una Historia ilustrada de la literatura española»:

Es este un viejo plan mío que ahora por primera vez me siento en vísperas de ver realizado. Como Vd. comprenderá, lo que me ha impedido hacerlo hasta ahora ha sido la falta de una persona, no ya preparada para semejante empresa, sino más bien que sintiera el entusiasmo necesario para llevarla a cabo, sin lo cual la preparación, por muy sólida que sea, sirve de bien poca cosa. Por todo lo que me ha dicho «Gaziel», así como por las referencias obtenidas de mi otro excelente amigo Jorge Rubió, creo que Vd. es la persona indicada para escribir esa obra. Le ruego, pues, me diga con toda sinceridad si realmente la «siente» Vd., es decir, si puede Vd. emprenderla a gusto, como si fuera cosa de pura afición. En caso favorable, le ruego tenga la bondad de examinar el adjunto borrador de contrato y me diga si está Vd. conforme con él. En el caso de que tenga que introducir alguna modificación, examinaré con todo interés todas las que Vd. me sugiera; y en el caso de que Vd., como yo creo, encuentre bien el contrato en la forma que se lo mando y que es la normal, podremos firmarlo en seguida, en cuanto, después de haberme Vd. comunicado un índice analítico de la obra y, a manera de muestra, uno cualquiera de sus capítulos, haya podido yo notificarle mi entera satisfacción. Esto, sin perjuicio de que, caso de que Vd. lo desee, pudiese $\mathrm{Vd}$. percibir las mensualidades expresadas en el contrato a partir de fines de agosto próximo.

La carta de presentación que GG le había llegado de VP — avalada por Calvet y Rubió - presentaba las mejores credenciales, pues sin llegar a conocerlo personalmente, se aventuró a adjuntarle el borrador del contrato. Por los términos en los que se refería el editor, da la impresión de que el proyecto fue una idea compartida entre él y su asesor; si hacía años había sido un «viejo plan» de GG, recientemente se lo habría también propuesto de forma más definida Calvet. En esta primera y apremiante misiva se adivina la esperanza que GG tenía de sacar a buen puerto una empresa que decía llevar abrigando desde hacía años, pero que no había tropezado aún con una personalidad de raza, con un historiador con la suficiencia y entereza para llevar a cabo el criterio de sensibilidad y el principio de compromiso que debían presidirla, pues en modo alguno debía petrificarse en los anquilosados métodos tradicionales de historia literaria que privilegiaban el dato enteco por encima del espíritu crítico.

A través del contrato anunciado, VP se comprometía a preparar en dos volúmenes (el primero entregado un año más tarde, y ocho meses después el segundo) una Historia ilustrada de la literatura española, «cuya extensión y contextura será aproximadamente iguales a las de la conocida Histoire illustrée de la littérature française, del profesor Gustave Lanson [...], comprometiéndose el Sr. Valbuena a darle la máxima calidad intelectual y literaria de que sea capaz». Según las condiciones pactadas, a medida que VP fuese redactando los capítulos, se los entregaría «mensualmente» a GG, junto con la «lista correspondiente de los respectivos grabados», responsabilidad que tam- 
bién le ocupaba al historiador. Por la cláusula tercera de este borrador -y en consonancia con la práctica editorial para obras de este carácter-, VP cedía a perpetuidad sus derechos de autor: «tanto el texto de la obra como la lista de los grabados con los epígrafes correspondientes, quedarán de la absoluta propiedad del Sr. Gili» ${ }^{13}$. GG le ofrecía a VP por su trabajo una «remuneración total y única» de «veinte mil pesetas». Como titular del proyecto, GG se reservó también el derecho de añadir «un tercer tomo acerca de las literaturas hispanoamericanas», que se lo podía encomendar a quien le pareciese «más conveniente».

Como trabajo de encargo, GG protegía el derecho de edición y reproducción de la obra, cuya propiedad intelectual quedaba reservada a nombre del autor, que en adelante siempre quedaría sujeto a las condiciones preferentes del editor. En su contestación, VP [R: 28-VII-1931] aprovechó para explicarle a GG que ese proyecto había sido ideado a la medida de sus fuerzas y voluntades:

Como le indicaba hace unos días a nuestro amigo «Gaziel», emprender esta tarea es uno de los mayores entusiasmos de mi carrera universitaria. La disposición del programa de mis cursos en las Universidades de La Laguna y Barcelona, en donde desde 1925 llevo explicando liter[atura] españ[ola], así como las series de conferencias dadas en la Universidad de Puerto Rico, se ha adaptado al proyecto que tengo desde hace muchos años de exponer nuestra gran Liter[atura] con arreglo a un criterio de sensibilidad e ideología que suele estar distante de nuestros tratadistas en estas materias, y que en cambio -aunque desde un punto de vista completamente español- se asemeja (en deseo, en intento, si no en realización) al del admirable manual de Lanson, que ha realizado perfectamente estos fines en la Historia de la Literatura Francesa.

Mis programas vienen a ser un índice del concepto que tengo de la asignatura. Por otra parte he tendido a unir la parte gráfica (retratos, portadas de ediciones, vistas de ciudades de ambiente adecuado, artes plásticas coincidentes) con la exposición literaria. Un ejemplo de este intento es mi manual de Lit[eratura] dramática, que ha publicado la editorial «Labor», y las conferencias con proyecciones en la Universidad americana citada.

Por lo tanto, con el mayor entusiasmo, creo «sentir» de verdad esta empresa, no faltando para ello trabajo y voluntad. Si no llega al fin de mis deseos no será por falta de estas condiciones previas.

Con estas referencias a sus asignaturas y monografías en las que había ensayado el método historiográfico que pretendía poner ahora en práctica, VP

${ }^{13}$ En el contrato del nonato volumen sobre la novela en España para la editorial Labor al que me he referido en páginas anteriores (y habría que pensar que de la misma forma con el de su Literatura dramática, editado en esa misma casa) se especificaba en su primera cláusula que VP cedía «definitivamente los derechos de edición del citado manual en idioma español y en portugués a "Editorial Labor, S. A."». Por esta obra VP habría recibido «la cantidad de mil quinientas pesetas, en concepto de honorarios por la cesión de derechos editoriales de la primera edición y seiscientas cincuenta pesetas por cada una de las ediciones siguientes». 
lanzaba un duro voto de censura contra los «tratadistas» de nuestra historia literaria y se postulaba como un nuevo hombre de letras que ajustado a determinados criterios de «sensibilidad e ideología» podría renovar explicativamente la historia literaria releyendo textos, géneros y movimientos desde el amplio horizonte de la historia de las manifestaciones artísticas. Aunque su historia de la literatura no contenía prólogo ni advertencia preliminar, páginas en las que habría sellado apodícticamente su ideal de historia literaria y las aspiraciones que con la suya pretendía alcanzar, varias declaraciones formalizadas en algunos ensayos historiográficos compuestos en torno a 1926 dan cuenta de la caracterización que para VP tenía el complejo ejercicio de historiar las formas literarias en gestación. En su libro La poesía española contemporánea, publicado en 1930, pero redactado en sustancia casi definitivamente en 1926, decía (1930: 21) lo que copio a renglón seguido:

Dada la dificultad de enjuiciar todo movimiento de arte todavía vivo y objeto de pasiones e incomprensiones, nuestra labor no puede ser más que un generoso propósito. Con todas las adiciones, con todas las rectificaciones que el tiempo y nuevas lecturas nos pueden obligar a hacer. Con todo, creemos que es preciso abordar estos temas vibrantes, clasificar y ordenar en lo que sea posible las reformas de arte actual.

En términos parejos se expresó (en González Ramírez, 2008: 683) en el discurso de inauguración al curso académico de La Laguna en octubre de 1926, cuando trató de fijar las aristas que caracterizaban la poesía canaria moderna:

Generalmente se hace de la historia literaria una seca enumeración de fechas y títulos, esqueleto erudito, empolvado y carcomido; se estudia lo muerto de la literatura. Y sin embargo lo esencial en el arte, como en la naturaleza, es el elemento que permanece vivo a través de los cambios circunstanciales, la voz del género y de la especie a pesar de las caducidades de los individuos.

Estas dos notas complementarias son lo suficientemente iluminadoras e ilustrativas para definir con argumentos contrastados el modelo de historia literaria que explícita e implícitamente propugnaba VP:

I. Su obra historiográfica no podía limitarse a perpetuar modelos clasificatorios de géneros y autores sin ponerlos en relación con otros fenómenos artísticos. La palabra «arte», como término críticamente marcado que se repite en los dos párrafos reseñados, representaba algo mucho más que la propia literatura nacional; la pintura, la música, la filosofía o la literatura universal son entendidas como fuerzas sinérgicas que gravitan sobre el eje motriz de su historia de la literatura, que no se entendería ni total ni parcialmente si se desatiende su marco histórico-artístico.

II. Había que desafiar al tiempo y a la crítica para llegar hasta las últimas manifestaciones literarias, ensayar una interpretación intuitiva, arriesgar en cada palabra definitoria, leer y explicar en tiempos casi paralelos al de la propia creación literaria; es decir, distanciarse de los modelos aplicados has- 
ta entonces por los últimos historiadores de la literatura como FiztmauriceKelly o Hurtado y González Palencia, que se quedaban en las postrimerías del XIX y en ocasiones practicaban — particularmente en el segundo caso- «una seca enumeración de fechas y títulos, esqueleto erudito, empolvado y carcomido».

III. Esta nueva forma de entender la historia, desde los orígenes hasta nuestros días, comportaba ciertos tropiezos, por lo que una relectura era consustancialmente necesaria para mantenerla en permanente estado de actualización, para corregir aquellas apreciaciones erróneas y rebajar o aumentar el tono dedicado a autores u obras que no se atuviesen al nuevo criterio de lectura adoptado.

Pero además, las líneas anteriormente seleccionadas son en definitiva el resultado de un proceso de exploración del método histórico-crítico que pretendía poner en marcha en algún momento y sobre el que había reflexionado en las memorias de oposición a cátedra que presentó en 1925. En una de ellas (de Teoría de la Literatura y de las Artes) alegaba VP que la «filosofía»servía como instrumento indispensable para «penetrar en lo íntimo» de los «fenómenos» histórico-artísticos. Ya en estas fechas pensaba que «la literatura no debe ser [...] algo arqueológico y muerto, sino que debe tener vida y actualidad», por lo que «no debemos seguir glorificando al siglo XIX como si fuera una gloriosa apoteosis y punto final de nuestra letras, no pasando de él». Para VP, la «orientación» que debía alcanzar un programa metodológico

[...] ha de ser de hoy y no de ayer. Evitaré cuanto pueda el lamentable espectáculo de terminar las explicaciones con los fenómenos estéticos de hace cincuenta años. [...] Con veintisiete años de estancamiento viven la mayor parte de los españoles, pues creen una gran innovación ponerse al tanto de la generación del 98. Superar esa generación. Sobre lo destruido, construir. Negar, para afirmar. Este es mi lema. Del criticismo a la creación. No hacer sentir al alumno un medio triste ante el que sólo toca resignarse o llorar. Hay que destruir muchos prejuicios de todo orden ${ }^{14}$.

Es también muy sugerente, en este mismo orden, la memoria que presentó a las oposiciones de las cátedras de Murcia y La Laguna, donde afirmaba que siempre había tendido «a un estudio» de la literatura «más intenso que extenso», en el que valoraba mucho más «las ideas adquiridas, la inquietud llevada al espíritu del alumno [...]; la sensibilidad afinada; la profundidad - cultural, integral — de nuestra labor, más que el amontonamiento de fechas y títulos». Se reafirmaba en su idea de que «el fenómeno literario» no podía ni debía «ser estudiado completamente aparte de todas las otras manifestaciones culturales». Y es justo al reparar en la necesidad de atender a los minori en la historia literaria y al reclamar la necesidad de acudir a las fuentes primarias cuando le ponía alguna tachadura al manual de Lanson:

${ }^{14}$ Archivo General de la Administración, Alcalá de Henares (Madrid), «[Expediente de oposición a] Teoría de la Literatura y de las Artes» [1925], Legajo 1490-52. Caja 31/16872. 
[...] al final del s. XIX se falseó la enseñanza y el estudio de la literatura. Se quiso reducir la literatura a una seca colección de hechos y fórmulas. Dependía este error pedagógico de otro más general: la concepción positivista de la filosofía y del arte, la visión cientificista de la literatura. [...] Más que los resúmenes o manuales importa conocer directamente las obras. En literatura francesa, por ej[emplo], el que se guíe sólo por el manual de Lanson, con ser uno de los más finos y construidos, apenas se fijaría en Gerard de Nerval, uno de los escritores de comienzos del XIX más próximos a la sensibilidad y gusto actuales ${ }^{15}$.

Estos fueron algunos de los principios rectores que activó VP cuando en torno a 1931 inició los primeros pasos que le conducirían a culminar en 1937 un admirable proyecto de vida. La deslumbrante obra que finalmente acabó culminando VP no surgió repentinamente tras la propuesta de GG; se trataba de un «viejo plan», podríamos decir, que también él acariciaba desde hacía tiempo. El azar cruzó en el espacio y el tiempo dos aspiraciones de una misma esencia: Gili buscaba a alguien que le diese forma y sentido al plan que tenía concebido desde hacía tiempo y Valbuena sentía la necesidad de reescribir la historia de la literatura prescindiendo de los arcaizantes modelos metodológicos y partiendo de unos principios totalmente personales y modernos. Esta magnífica alianza dio como resultado una de las obras más extraordinarias, brillantes y emblemáticas de la historiografía literaria; una obra que colocó a Valbuena como criterio de autoridad en la filología española; y una obra, en definitiva, que representa un capítulo fundamental en la historia de la editorial Gustavo Gili.

En esta sugerente carta de VP, en la que mostraba su satisfacción y confianza para afrontar esta obra de conjunto, el historiador solicitaba «que la remuneración fuese de 25.000 pesetas» (principalmente, según le explicaba, para cubrir algunos gastos de viajes a Madrid que tenía que hacer para leer y estudiar «la parte referente a autores cuyas ediciones no se hallan en Barcelona, y las ilustraciones de los capítulos más difíciles»), recompensándole a cambio con aumentar la extensión del trabajo. También matizaba que la cláusula referente al tomo de la literatura hispanoamericana debía completarse con algún agregado que le asegurase hacerse cargo él mismo de las revisiones del texto sobre la literatura española, que debían ser remuneradas según un acuerdo por parte de ambos: «Esta última parte se refiere más bien al entusiasmo y cariño que me inspira la obra, y a la posibilidad, no mientras figure $\mathrm{Vd}$. al frente de la editorial, si no ante posibles contingencias ajenas en el futuro a su voluntad, de poder admitir otras modificaciones».

GG [8-VIII-1931] justificaba sus honorarios esgrimiendo los serios aprietos de sacar a flote un proyecto como el presente, y esgrimía como agravante «la situación que actualmente atraviesa la industria editorial como consecuen-

${ }^{15}$ Archivo General de la Administración, Alcalá de Henares (Madrid), «Expediente de oposiciones a Lengua y Literatura española de Murcia y La Laguna» [1925], Legajo 5399, Expediente 1, Caja 32/7423. 
cia de la crisis económica mundial». Volvía sobre sus argumentos haciendo hincapié en el «gran esfuerzo» y «riesgo» que suponía esta empresa, «en la que pensaba hace años» y a la que se lanzaba «gustoso [...] por el entusiasmo que siento [...] y por haber tenido por fin la fortuna de encontrar el autor soñado en quien concurren la competencia y el ideal». Como propuesta compensatoria, GG ofrecía añadirle al contrato una cláusula por la que quedaba obligado «a satisfacerle la cantidad de cinco mil pesetas por la revisión, complementos, remaniements y corrección de pruebas de cada nueva edición»; «y Vd. se verá compensado - terminaba diciéndole en su carta - si la obra obtiene el éxito que confiadamente cabe esperar por el interés de la materia, la bondad del texto, la belleza de las ilustraciones y el esmero de la edición en la que pondré el mayor cuidado». VP [23-VIII-1931] le agradeció que hubiese tenido en consideración sus sugerencias y aceptó los términos encomendándose a «la confianza que tengo en Vd. y el entusiasmo por la obra a realizar». En tal fecha, le anunciaba ya que estaba «terminando de redactar el índice general de materias del proyecto del libro», y que pasado unos días le remitiría la redacción de «alguna parte de la obra, para que pueda Vd. ver su orientación».

Será a principios del siguiente año cuando GG [11-II-1932] le remita al autor el nuevo borrador del contrato — que daba por «definitivo»- de la Historia ilustrada de la literatura española. Fue esta versión la que terminó firmándose, y, con respecto a la versión primitiva, se ajustó la extensión de la obra y se agregó una cláusula sobre los honorarios de las revisiones de la obra según la indicación que VP le hizo, pero matizaba (con vistas a los posibles reveses en el futuro) que si el autor no asumía la responsabilidad de revisión y corrección «al cabo de tres meses del debido requerimiento», el editor quedaba «en completa libertad para encargar dicho trabajo a quien mejor le pareciese». Sellado ya el contrato, VP debía entregar regularmente los capítulos de la obra y recibir su compensación mensual correspondiente. Varios meses más tarde, y debido a la ausencia de noticias que GG tenía del autor, decidió escribirle [15-VII-1932] mostrándole su deseo de que disfrutase «de la mensualidad asignada, tanto si me trae $\mathrm{Vd}$. original, como si se lo guarda». Pero no disimulaba su desazón al interpretar que este prolongado silencio pudiese deberse a que VP no había comenzado a «trabajar en su obra». Con esta llamada de atención a los pocos meses de ajustadas las condiciones del contrato, GG, experimentado en la brega de autores y grandes proyectos, asumía seriamente sus funciones de gerente de la editorial y le mandaba a VP un mensaje doble basado en la confianza que le dispensaba y en la responsabilidad que esperaba. 


\section{LA HiSTORIA DE LA LITERATURA ESPAÑOLA EN CIERNES: CONTRATIEMPOS Y DEMORAS}

A partir de mediados de 1932, el diálogo epistolar es muy inconstante y fragmentario, pues sería sustituido probablemente por las entrevistas personales. Sin embargo, la ultimación del proyecto se vio afectada por la situación académica de VP (que durante los dos cursos siguientes, 1933-34 y 1934-35, estuvo ocupando un lectorado en el Departamento de Español en Cambridge ${ }^{16}$ ) y por las dimensiones que fue adquiriendo la obra. Será ya a finales de ese año [29-XI-1934] cuando VP le anuncie por tarjeta postal desde Cambridge que había concluido la «Literatura española, al fin de octubre, como le dije». Le avisaba de que en su próxima visita a Barcelona le llevaría «los capítulos» que completarían la obra. También, y debido a las urgencias que el editor venía mostrando en los últimos meses, le sugería que «si se hace la obra en dos tomos, pueden ya empezar con el $1^{\circ}$, pues podría desde esa [ciudad] corregir las pruebas. Aun de ser en dos, como ya está todo el original, pueden, si le parece, comenzar las primeras galeradas. Ahora estoy corrigiendo lo hecho, pues se hizo con gran rapidez y lo exige». La fecha que marca esta carta - muy alejada de las fundadas sospechas que hasta ahora se tenían sobre la finalización de la Historia- demuestra que VP trabajó a uña de caballo al terminar el original del texto. Aunque después lo retocase y ampliase, como ponen de relieve las adiciones bibliográficas posteriores a 1934 que aparecen en el tomo primero, en sustancia la obra estaba en lo fundamental preparada y concluida en estas fechas. Si en primer término la Historia en boceto se había planificado con un determinado alcance y profundidad, la realización en manos de Valbuena, que acometió un trabajo hercúleo y lo finalizó verdaderamente en un tiempo prodigioso, superó toda la expectación que había puesto el editor sobre ella.

Al año siguiente, en 1935, GGj [4-V-1935] le explicaba a VP su deseo inminente de «dar pronto a la imprenta el original», pero se habían tropezado con un serio escollo: «hemos empezado a hacer una revisión de las cuartillas escritas a máquina, encontrando que su última entrega es en gran parte ilegible a causa de haberse hecho con la cinta de la máquina excesivamente gastada». Desde Cambridge, VP se ofrecía para solventar estas pequeñas adversidades, que, según entendía [8-V-1935], serían fáciles de resolver, «pues

${ }^{16}$ En su Historia de la literatura española se advierte un reflejo de esta estancia (para cuyo primer año académico VP solicitó una pensión a la Junta de Ampliación de Estudios) en algunos capítulos. Como ejercicio de recreación para imaginar «lo que era la vida universitaria en la España de fray Luis», VP (1937, I: 482) sugería «pensar en las universidades que aun hoy conservan su aspecto de tradición medieval, en su constitución y vida escolar, como las de Oxford y Cambridge en la Inglaterra de hoy». Por otra parte, «la ciudad vaga de tinieblas y bicicletas» que evocaba un poema de Guillén, «Noche céntrica», no podía ser, según la apreciación de VP (1937, II: 943), «más que inglesa —Oxford o Cambridge». 
creo que las copias salieron más claras». En esta revisión que se estaba haciendo de los materiales presentados se había también detectado algunas lagunas y otras anomalías que GG le comentaba a VP por carta [20-V-1935]. Faltaban algunos capítulos, mientras que otros contenían «la numeración repetida»; «además los títulos que figuran en un índice de materias, al cual hemos recurrido para aclarar este embrollo, no coinciden casi nunca con los de los capítulos que Vd. nos ha ido entregando sucesivamente». Parece evidente que ese índice primitivo que VP compuso había sido alterado (al menos en sus epígrafes) en el curso de la preparación de la obra, y para GG esto suponía una complicación añadida. Por todo ello, el editor le rogaba a VP solucionar en un próximo encuentro estos asuntos, porque «difícilmente lograríamos por correspondencia aclararlo todo»; «sin aclarar previamente estos puntos», GG veía seriamente complicado «dar el original a la imprenta, ya que ello ocasionaría luego correcciones y recorridos en la composición tan costosas como molestas de hacer».

Las últimas cartas que se han conservado de esta primera época pertenecen al verano de 1935 (desde esta fecha y hasta la posguerra hay una inmensa laguna en la correspondencia que nos impide conocer los últimos detalles de edición, reconstruibles tan solo a partir de algunas constataciones y ciertas conjeturas). Con VP en Barcelona para supervisar la edición de la obra y corregir las pruebas de imprenta, es difícil imaginar que los dos tomos no se hubiesen compuesto tipográficamente y tirado con anterioridad a 1937. Parece claro que los capítulos que GG reclamaba tardaron más de lo previsto por su autor en ser revisados y entregados en su versión definitiva; además aunque VP desde que se comprometió contractualmente en 1932 a la redacción de la obra no hizo prácticamente más que dedicarse a ella (hallándose un importante hiato en sus contribuciones bibliográficas desde ese año hasta la publicación de la Historia en 1937), es cierto que en los años más cercanos a esta fecha adquirió algunas responsabilidades ${ }^{17}$. Presumiblemente en 1936 la imprenta ya estaba componiendo el original, pero el estallido de la Guerra Civil trajo consigo meses más tarde el primer intento de exilio de Valbuena a Liverpool (Reino Unido), un hecho que paralizó irremediablemente el curso de la edición ${ }^{18}$.

Ya en 1937, de regreso el autor en Barcelona, se retomarían las labores de corrección, seriamente obstaculizadas por las lamentables circunstancias,

${ }^{17}$ Colaboró por ejemplo en el homenaje a Rubió i Lluch (1936), estuvo preparando su Historia de la poesía canaria (editada finalmente en 1937, y que configuró en buena medida con materiales que ya tenía publicados) y, después de ser nombrado en Francia Officer d'Académie en 1934, participó en el Repértoire chronologique des Littératures modernes (1937).

${ }^{18}$ En los avales del expediente de depuración que VP presentó se acredita la presencia del historiador en Reino Unido durante los meses de noviembre y diciembre de 1936. Sin embargo, en su pasaporte conservado, en el que se registran todas sus entradas a este país desde octubre de 1933 hasta 1939, esta estancia de 1936 no aparece consignada. 
que impidieron que los dos tomos de la obra saliesen antes de finales de año. Este hecho, sin embargo, permitió que VP retocase su obra en pruebas de imprenta hasta mediados de 1937. Si atendemos a la bibliografía de los capítulos de la Historia que alcanzan hasta el siglo XIX, los estudios más recientes citados son de principios de los años treinta. Conociendo la laboriosa operación editorial que supone la composición, revisión, impresión y encuadernación de una obra en dos tomos, es plausible que el primero empezase a componerse en galeradas a finales de 1935 , pero me inclino más a pensar que el proceso de composición se iniciaría ya en 1936, año en el que el autor estaba probablemente corrigiendo las primeras pruebas. La noticia bibliográfica más reciente que en este primer volumen encontramos se halla a propósito de la interpretación de las églogas de Juan del Encina (I: 335) ${ }^{19}$, lugar en el que VP aprovecha para trazar una comparativa con la temática que se desarrolla en el teatro francés, del que cita como ejemplo la edición parisina de Le jeu de Robin et Marion de Adam de la Halle cuidada por J. Cohen y editada en 1935.

Para entender el proceso de ultimación y composición del segundo tomo hay que tener en consideración otras circunstancias. VP estaría perfilando los capítulos finales de su libro (desde Ortega y Gasset y la escuela de Menéndez Pidal hasta las últimas formas literarias en la poesía, el teatro y la prosa), que aunque tendría redactados en grueso (las páginas de los dos últimos capítulos traslucen las líneas maestras de su libro La poesía española contemporánea, pero muy refundidas y aumentadas, y también permiten leer entrelíneas algunos otros trabajos menores suyos ${ }^{20}$ ), debía completar y actualizar, pues el retraso en la composición editorial del texto le obligó a trabajar paralelamente en la corrección de las galeradas del primer tomo y en la lectura e interpretación de las obras más recientes de sus contemporáneos. Si quería presentar una Historia puesta al día, no podía consentir que obras tan importantes como La destrucción o el amor de Aleixandre, Yerma de García Lorca o Espejo de avaricia de Aub (todas aparecidas en 1935) no gozasen de una atención crítica. Pero lo más sorprendente es que en las difíciles fechas de 1936 todavía tuvo tesón para hacer sugerentes lecturas de obras editadas durante ese año, como Razón de amor de Salinas o la segunda edición de Cántico de Guillén. VP, en unas fechas en las que la circulación de libros todavía no se había visto demasiado afectada, mantenía el pulso por mantener actualizada su obra; en ningún caso estaba dispuesto a permitir que este tipo

${ }^{19}$ En adelante citaré entre paréntesis el tomo y la página de la Historia de la literatura española (1937).

${ }^{20}$ Además de las lecturas sobre los poetas más actuales que aparecen en su libro sobre la poesía contemporánea, VP no se despegó de las corrientes poéticas de su época, y, en torno a los años treinta, le dedicó ensayos a Antonio Espina, a los poetas del 98, a Tomás Morales, a Josep Maria Lòpez-Picó o a Domingo Rivero. Algunos de estos textos han sido ahora recogidos en el volumen que R. Malpartida Tirado y yo hemos publicado recientemente (Valbuena Prat, 2011). 
de contingencias empañasen una labor firme y sostenida durante los últimos años.

A diferencia del primer volumen, en el segundo no es infrecuente encontrar indicaciones a artículos y libros aparecidos en 1935 o incluso en 1936. En el capítulo dedicado a Lope de Vega, VP incorporó selectivamente la bibliografía aparecida durante el IV centenario celebrado en 1935. Del año siguiente encontramos una importante gavilla de trabajos citados, como la traducción al español de varias monografías alemanas (Lope de Vega en Alemania de Farinelli, II: 255; o El dinamismo en la obra de Pereda de Gerda Outzen, II: 750); el estudio sobre Guillén de Rosselló-Porcel, ayudante suyo en la cátedra de Barcelona, aparecido en los Cuadernos de la Facultad de Filosofía y Letras (II: 951); o los trabajos de algunos amigos como Castro y Calvo, Piquer y la interpretación clásica de la calenturas (II: 588), y Díaz-Plaja, cuyas últimas publicaciones (Introducción al estudio del romanticismo español y El arte de quedarse solo y otros ensayos) aparecen también referenciadas (II: 599, 629 y 933). Este segundo tomo se cerraba con la mención a la historia de la «lírica, próxima a publicarse, de Díaz-Plaja» (II: 985), que vería la luz, en los manuales de la editorial Labor, también en 1937.

Algunas de estas menciones bibliográficas fueron añadidas por VP en pruebas de imprenta, pues la mayoría de las que corresponden a la última parte del libro (la literatura contemporánea) no aparecen indizadas (como las referencias arriba citadas de Castro y Calvo, Rosselló-Porcel o la colección de ensayos de Díaz-Plaja, pero tampoco se localizan otros nombres propios, como el mismo de Agustí Calvet). Otras que sí se encuentran registradas están localizadas en la página posterior a la indicación expresa, sin duda porque los añadidos últimos en el cuerpo de la obra desplazaron la composición en galeradas sobre la que se había configurado el índice. De entre estas adiciones de última hora hay algunas que resaltan porque son significativamente relevantes para determinar sobre qué fechas la obra seguía estando en imprenta a falta, seguramente, de tirarse los últimos pliegos. Al tratar de Unamuno, VP advertía en nota (II: 839) lo siguiente: «Esta semblanza de Unamuno ha sido escrita antes de julio de 1936, y por lo tanto de su muerte, ocurrida en Salamanca el 1 de enero de 1937». A continuación citaba la noticia del fallecimiento que se había publicado en el número inaugural de Hora de España, «la revista al servicio del pueblo», y un artículo de J. F. Montesinos en la misma revista sobre la figura del autor de Niebla que se recogió en el número del mes de abril. De esta misma publicación, que estaba consultando y leyendo en estas fechas, VP añadió un ensayo sobre Goya de Bergamín, «Pintar como querer» (II: 974), que apareció en el quinto número, correspondiente a mayo.

Con estas notas añadidas, que nos sitúan en fechas muy concretas en las que el texto estaba siendo corregido, se puede concluir que la Historia de la literatura española no apareció antes de las vacaciones veraniegas. La situación social se empezaba a recrudecer por estas fechas y en Barcelona se des- 
ataron los primeros conflictos internos a causa de la guerra en los primeros días del mes de mayo de 1937, con el resultado de varios asesinatos políticos y algunos centenares de muertos (Casanova, 2007: 15). La obra salió al mercado en los últimos meses del año; en ese momento, Dámaso Alonso [22-XII1937] le escribía a VP lo que aquí transcribo: «Me entero de que ha salido tu libro. Espero que a este reseñador de obras tuyas no le faltará su ejemplar. (El precio de la obra me asusta). Aquí no ha llegado todavía a las librerías: en cuanto llegue haré que lo compren las bibliotecas universitarias» ${ }^{21}$. La ausencia de reseñas en el año de la publicación de la obra y el contenido de esta carta inédita del editor de Góngora recientemente descubierta son una prueba más que se une a las noticias sobre el proceso de composición desprendidas de las inexactitudes u omisiones en el «Índice alfabético general» ${ }^{22}$.

\section{BIBLIOGRAFÍA CITADA}

Allison Peers, Edgar (1938). [Reseña a Á. Valbuena Prat, Historia de la literatura española, 1937], Bulletin of Spanish Studies. XV, 58, abril, pp. 111-114.

Casanova, Julián (2007). «Mayo de 1937», El País. 3 de mayo, p. 15.

Castellano, Philippe (2013). «Orígenes y primeros pasos de la Editorial Gustavo Gili», en Mònica Gili, Moisés Puente y Marta Rojals (eds.), Editorial Gustavo Gili. Una historia 1902-2012. Barcelona: Gustavo Gili, pp. 13-31.

Díez Canedo, Enrique (1938). [Reseña a Á. Valbuena Prat, Historia de la literatura española, 1937], La Vanguardia. 26 de abril, p. 3.

Díez de Revenga, Francisco Javier, y Francisco Florit Durán (coords.) (2000). «Ángel Valbuena Prat y la historiografía literaria española», Monteagudo, 5.

Gili i Roig, Gustavo (1944). Bosquejo de una política del libro. Barcelona: Gustavo Gili.

González del Valle, Juan (1938). [Reseña a Á. Valbuena Prat, Historia de la literatura española, 1937], Hora de España. XVIII (junio) y XIX (julio), pp. 67-70 y pp. 79-80.

González Ramírez, David (2007a). «Un enigma descifrado en la historiografía española: vicisitudes y peripecias de la Historia de la literatura española (1937-39) de Ángel Valbuena Prat», Analecta Malacitana. XXX, I, pp. 125-147.

González Ramírez, David (2007b). La historiografía literaria española y la represión franquista. Ángel Valbuena Prat en la encrucijada. Málaga: Universidad de Málaga.

González Ramírez, David (2008). «La historia de la poesía canaria en ciernes: el discurso inaugural del curso académico 1926-1927 de La Laguna pronunciado por Á. Valbuena Prat», Analecta Malacitana. XXXI, 2, pp. 673-708.

González Ramírez, David (2012). «Génesis de un proyecto historiográfico. Correspondencia inédita entre Ángel Valbuena Prat y Gustavo Gili i Roig (1931-1935)», en David González

${ }^{21}$ Dámaso, que ocupaba la cátedra de Lengua y Literatura en la Universidad de Valencia desde 1933, había reseñado tanto los dos tomos de los Autos sacramentales de Calderón como La poesía española contemporánea en las páginas de Revista de Filología Española.

${ }^{22}$ Ofrezco aquí el listado de reseñistas que conozco de la primera edición de la obra: Díez Canedo (1938), Allison Peers (1938), González del Valle (1938), Michels (1938), Serís (1939) y Griswold Morley (1939). 
Ramírez (ed. y coord.), Lienzos de la escritura, sinfonías del recuerdo. El magisterio de Ángel Valbuena Prat. Málaga: Anejos de Analecta Malacitana, pp. 205-229.

González Ramírez, David (2013). «Un "viejo plan” de Gustau Gili Roig: la Historia de la literatura española de Ángel Valbuena Prat», en Mònica Gili, Moisés Puente y Marta Rojals (eds.), Editorial Gustavo Gili. Una historia 1902-2012. Barcelona: Gustavo Gili, pp. $97-125$.

González Ramírez, David (en prensa a). «La Historia de la literatura española de Á. Valbuena Prat paso a paso (II): la edición encubierta de la posguerra (¿1939?)», Bulletin of Spanish Studies.

González Ramírez, David (en prensa b). «La Historia de la literatura española de Á. Valbuena Prat paso a paso (III): revisión y decadencia de una obra "más humana que erudita" (1946-1968)», Nueva Revista de Filología Hispánica.

González Ramírez, David (en prensa c). «La Historia de la literatura española de Á. Valbuena Prat paso a paso (IV): addenda et corrigenda (1946-1968)», Crítica Hispánica.

González Ramírez, David (en prensa d). «La Historia de la literatura española de Á. Valbuena Prat paso a paso (V): complementos y revisión final», Il Confronto Letterario.

Griswold Morley, Sylvanus (1939). [Reseña a Á. Valbuena Prat, Historia de la literatura española, 1937], Hispanic Review. VII, 2, abril, pp. 175-178.

Lara Garrido, José (2007). «Ángel Valbuena Prat o el alba de una historiografía perdida», en David González Ramírez, La historiografía literaria española y la represión franquista. Ángel Valbuena Prat en la encrucijada. Málaga: Universidad de Málaga, pp. 7-36.

Lara Garrido, José (2012). «La Historia de la literatura española (1937) de Ángel Valbuena Prat: ensayo de deslindes sobre el método historiográfico y la construcción crítica», en David González Ramírez (ed. y coord.), Lienzos de la escritura, sinfonías del recuerdo. El magisterio de Ángel Valbuena Prat. Málaga: Anejos de Analecta Malacitana, pp. 231-337.

Llanas, Manuel (1998). Gaziel: vida, periodisme i literatura. Barcelona: Publicacions de l'Abadia de Montserrat.

Llanas, Manuel (2005). L'edició a Catalunya: el segle XX (fins a 1939). Barcelona: Gremi d'editors de Catalunya.

Llanas, Manuel (2006). L'edició a Catalunya: el segle XX (1939-1975). Barcelona: Gremi d'editors de Catalunya.

Martín Ezpeleta, Antonio (2008). «Ángel Valbuena Prat», en Las «Historias literarias» de los escritores de la Generación del 27. Madrid: Arco/Libros, pp. 91-196.

Martín Ezpeleta, Antonio (2012). «La última etapa del historiador de la literatura Ángel Valbuena Prat», en David González Ramírez (ed. y coord.), Lienzos de la escritura, sinfonías del recuerdo. El magisterio de Ángel Valbuena Prat. Málaga: Anejos de Analecta Malacitana, pp. 407-443.

Martínez Rus, Ana (2003). La política del libro durante la Segunda República. Socialización de la lectura. Gijón: Trea.

Massot i Muntaner, Josep (2005). Jordi Rubió i Balaguer, semblança biográfica. Barcelona: Institut d'Estudis Catalans.

Massot i Muntaner, Josep (2005-2006). «Antoni Rubió i Lluch vist pel seu fill Jordi», Boletín de la Real Academia de Buenas Letras de Barcelona. 50, pp. 297-328.

Michels, R. J. (1938). [Reseña a Á. Valbuena Prat, Historia de la literatura española, 1937], Hispania. XXI, 3, octubre, p. 231.

Padilla Chasing, Iván V. (2003). «Gustave Lanson: símbolo y alegoría de la Historia literaria», Literatura: teoría, historia, crítica. 5, pp. 149-161.

Palomo, Pilar, y Antonio Prieto (2000). «Historia de una Historia y evocación de Ángel Valbuena Prat», Monteagudo. 5, pp. 13-27.

Permanyer, Lluis (1989). «La dinastía de los Gili, señores del libro», La Vanguardia. 29 de enero, p. 36. 
Pozuelo Yvancos, José María (2000). «Ángel Valbuena: la renovación de la historiografía literaria española», Monteagudo. 5, pp. 51-69.

Rubió i Balaguer, Jordi (1953). «La literatura catalana», en Guillermo Díaz Plaja (coord.), Historia general de las literaturas hispánicas, III. Barcelona: Barna, pp. 727-930.

Rubio Tovar, Joaquín (2004). «Texto, historia y sociedad. La obra de Lanson», en La vieja diosa. De la Filología a la posmodernidad. Alcalá de Henares: Centro de Estudios Cervantinos, pp. 92-103.

Serís, Homero (1939). [Reseña a Á. Valbuena Prat, Historia de la literatura española, 1937], Book Abroad. XII, 1, pp. 98-99.

Serrano Asenjo, Enrique (2006). «Historia y punición: Ángel Valbuena Prat, depurado», Revista de Literatura. LXVIII, 135, 2006, pp. 249-259.

Valbuena Prat, Ángel (1930). La poesía española contemporánea. Madrid: CIAP.

Valbuena Prat, Ángel (1937). Historia de la literatura española. Barcelona: Gustavo Gili.

Valbuena Prat, Ángel (1974-1979). Literatura castellana. Los grupos geográficos y la unidad literaria, I-II. Barcelona: Juventud.

Valbuena Prat, Ángel (2011). En el horizonte crítico del 27: ensayos rescatados (1927-1932). Ed. y pról. de David González Ramírez y Rafael Malpartida Tirado. Murcia: Real Academia Alfonso X el Sabio.

Wellek, René (1988). Historia de la crítica moderna (1750-1950). La segunda mitad del siglo XIX, IV. Madrid: Gredos, pp. 95-99.

\section{Archivos consultados}

Archivo Editorial Gustavo Gili (Barcelona) [Correspondencia entre Ángel Valbuena Prat y Gustavo Gili i Roig, Gustavo Gili Esteve y Agustí Calvet].

Archivo General de la Administración (Alcalá de Henares, Madrid). «[Expediente de oposición a] Teoría de la Literatura y de las Artes» [1925], Legajo 1490-52. Caja 31/16872.

Archivo General de la Administración (Alcalá de Henares, Madrid), «Expediente de oposiciones a Lengua y Literatura española de Murcia y La Laguna» [1925], Legajo 5399, Expediente 1, Caja 32/7423.

Biblioteca Arxiu Rubió (Barcelona) [Correspondencia entre Ángel Valbuena Prat y Antoni Rubió i Lluch y Jordi Rubió i Balaguer].

Fecha de recepción: 13 de junio de 2012

Fecha de aceptación: 10 de enero de 2013 